Check for updates

Cite this: Chem. Commun., 2018, 54,172

Received 20th October 2017 Accepted 30th November 2017

DOI: $10.1039 / c 7 c c 08104 a$

rsc.li/chemcomm

\section{Manipulating and quantifying spin states in solution as a function of pressure and temperature $\dagger$}

\author{
Ross W. Hogue, (DD ${ }^{a}$ Christopher P. Lepper, ${ }^{b}$ Geoffrey B. Jameson (D) $*^{b}$ and \\ Sally Brooker (D)*a
}

\begin{abstract}
Monitoring the spin states of species in solution is a crucial aspect of understanding magnetic properties as well as spin-labile sensing, supramolecular, catalytic and biochemical processes. Herein, we describe the first quantitative variable-pressure and variabletemperature method of determining spin states in solution, demonstrate that it is accurate, and identify a simultaneous $T$ and $P$ sensor system.
\end{abstract}

Determining the spin state of a system is fundamental to understanding its magnetic properties and chemical reactivity. The study of molecular magnetic phenomena ${ }^{1}$ relies upon the measurement of spin states under different conditions. Understanding reactivity ${ }^{2}$ and catalytic processes ${ }^{3}$ is greatly aided by being able to determine the spin states of various reactants, intermediates and products. Measurements of spin states in the solution phase are of particular importance, especially for the study of biologically relevant processes, including photosynthesis ${ }^{4}$ and iron-containing enzyme activity, ${ }^{5}$ noting that life persists at pressures in excess of $100 \mathrm{MPa}(\sim 1000$ atmospheres). However, there is no established method of quantifying spin states in solution as a function of both pressure and temperature.

The application of hydrostatic pressure to spin-labile compounds typically favours the low spin (LS) state due to the smaller molecular volume compared to the high spin (HS) state. ${ }^{6}$ While this has been observed in pressure-induced solution spin crossover (SCO), by the Gouy method, ${ }^{7}$ and $\mathrm{UV}_{\text {-vis }}^{8}$ and ${ }^{1} \mathrm{H} \mathrm{NMR}^{9}$ spectroscopies, these have all been qualitative measures of spin states. Herein, we establish a method for the accurate quantitative measurement of spin states in

\footnotetext{
${ }^{a}$ Department of Chemistry and MacDiarmid Institute for Advanced Materials and Nanotechnology, University of Otago, PO Box 56, Dunedin 9054, New Zealand. E-mail: sbrooker@chemistry.otago.ac.nz

${ }^{b}$ Chemistry - Institute of Fundamental Sciences and MacDiarmid Institute for Advanced Materials and Nanotechnology, Massey University, Private Bag 11 222, Palmerston North 4442, New Zealand. E-mail: G.B.Jameson@massey.ac.nz $\dagger$ Electronic supplementary information (ESI) available: Synthesis, high pressure instrumentation, detailed NMR data collection and processing, and X-ray crystallography. CCDC 1554635. For ESI and crystallographic data in CIF or other electronic format see DOI: $10.1039 / \mathrm{c} 7 \mathrm{cc} 08104 \mathrm{a}$
}

solution at variable pressures and temperatures, by extension of the ambient pressure Evans ${ }^{1} \mathrm{H}$ NMR 'tube-in-tube' method ${ }^{10}$ to enable the use of a 'single-tube' that can be pressurised to $240 \mathrm{MPa}$. In addition to quantitative spin-state information, the ${ }^{1} \mathrm{H}$ NMR spectra themselves can also yield useful chemical and 3D structural information about the subject complex. ${ }^{11}$ Thus, this method adds spin-state capabilities to high-pressure NMR techniques such as those already applied to host-guest, ${ }^{12}$ catalytic, ${ }^{13}$ and biomacromolecular systems. ${ }^{14}$

In order to develop this method of quantifying solution spin states under pressure, three of our recently reported solution-phase (thermally-induced) SCO-active dinuclear iron(II) complexes of 4-substituted-3,5-bis $\{[(2-$ pyridylmethyl)-sulfanyl $]$ methyl $\}-4 H-1,2,4$ triazole (PSRT) ligands, where $\mathbf{R}=\mathrm{Ph},{ }^{\mathrm{Me}} \mathrm{Ph}$ or ${ }^{\mathrm{i}} \mathrm{Bu}$, i.e. $\left[\mathrm{Fe}_{2}(\mathbf{P S P h T})_{2}\right.$ ]$\left(\mathrm{BF}_{4}\right)_{4},\left[\mathrm{Fe}_{2}\left(\mathbf{P S}{ }^{\mathbf{M e}} \mathbf{P h T}\right)_{2}\right]\left(\mathrm{BF}_{4}\right)_{4}$, and $\left[\mathrm{Fe}_{2}\left(\mathbf{P S}^{\mathbf{i}} \mathbf{B u T}\right)_{2}\right]\left(\mathrm{BF}_{4}\right)_{4}$ (Fig. 1), were investigated by high-pressure ${ }^{1} \mathrm{H}$ NMR spectroscopy. Spectra were recorded in $\mathrm{CD}_{3} \mathrm{CN}$ solution at $30 \mathrm{MPa}$ intervals between $0.1 \mathrm{MPa}$ (atmospheric pressure) and $240 \mathrm{MPa}$, and at 5 different temperatures in the range of $278-313 \mathrm{~K}$.

In each spectrum (Fig. 2 and Fig. S1-S3, ESI $\dagger$ ), very broad and highly downfield shifted (up to $\sim 100 \mathrm{ppm}$ ) proton signals typical of a paramagnetic substance are observed, indicating population of the HS state. As pressure is increased, these downfield signals shift upfield or towards a "normal" position expected for a diamagnetic material, indicating that a pressureinduced SCO towards the LS state occurs. At $240 \mathrm{MPa}$, the

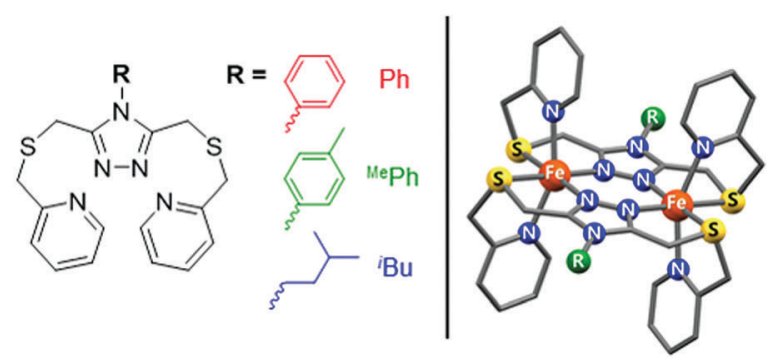

Fig. 1 PSRT ligand with the three $\mathbf{R}$ groups used in this study (left), and the structure of the $\left[\mathrm{Fe}_{2}(\mathbf{P S R T})_{2}\right]^{4+}$ cations (right). 


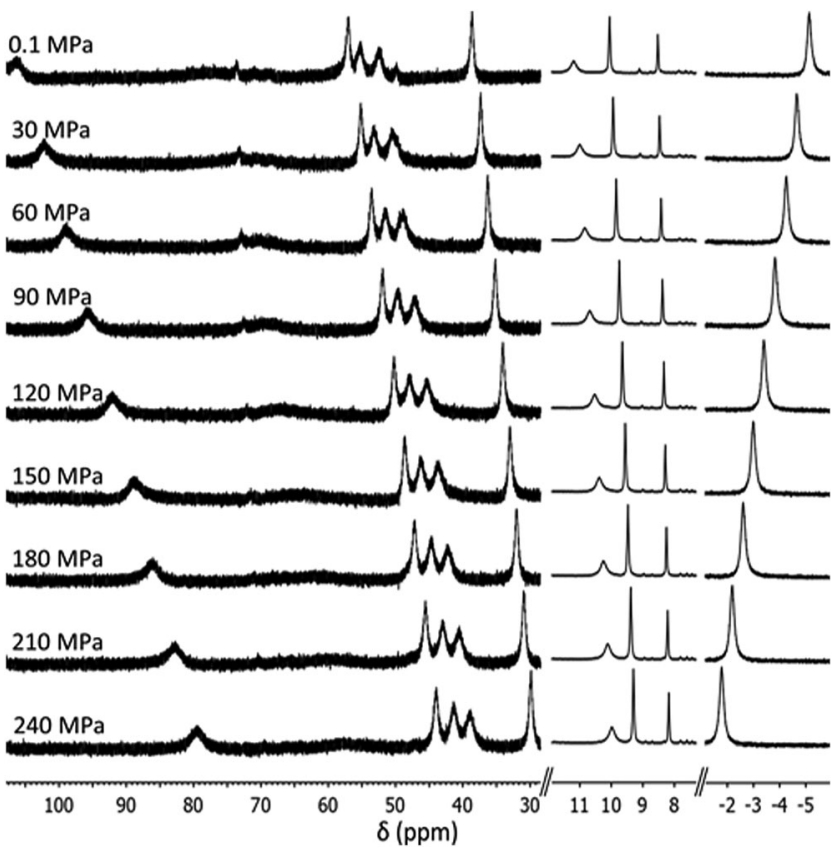

Fig. 2 Stacked ${ }^{1} \mathrm{H}$ NMR spectra of $\left[\mathrm{Fe}_{2}(\mathrm{PSPhT})_{2}\right]\left(\mathrm{BF}_{4}\right)_{4}$ in $\mathrm{CD}_{3} \mathrm{CN}$ solution showing a qualitative $\mathrm{SCO}$ at room temperature (293 K) from $0.1 \mathrm{MPa}$ (top) to $240 \mathrm{MPa}$ (bottom). Note that the spectra have been truncated to highlight the downfield shifted signals of some methylene and pyridyl protons (left) and phenyl protons (centre), and the upfield shifted pyridyl proton signal (right). For the full spectra, see Fig. S1, ESI.†

proton signals are still relatively far downfield, indicating that a significant population of the HS state remains, consistent with the SCO being incomplete within the pressure range studied. Proton signals that were shifted upfield by the paramagnetism (to $\sim-5 \mathrm{ppm}$ ) concomitantly move downfield towards their diamagnetic values as pressure is increased.

To quantitatively analyse the spin states at each pressure, we turned to the Evans method which under standard conditions (ambient pressure) uses a tube-in-tube experiment. The inner tube contains pure deuterated solvent and the outer tube contains the paramagnetic material in the same solvent. The frequency shift of the solvent signal, $\Delta f$, in the outer tube compared to the pure solvent (to which the NMR spectrum is locked), is dependent on the magnetic susceptibility of the paramagnetic material, and hence $\chi_{\mathrm{M}} T$ can be calculated from $\Delta f(\mathrm{~Hz})$, the concentration $m\left(\mathrm{~g} \mathrm{~cm}^{-3}\right)$, and the spectrometer frequency $f(\mathrm{~Hz})$ using the Evans method (eqn (1)) to obtain the mass susceptibility $\chi_{\mathrm{g}}\left(\mathrm{cm}^{3} \mathrm{~g}^{-1}\right) .^{10,15}$

$$
\chi_{\mathrm{g}}=3 \Delta f /(4 \pi m f)
$$

However, an inner tube is not feasible with our high-pressure cell and zirconia NMR tube, or for that matter with most high-pressure NMR setups, which typically involve specialised thick-walled glass or sapphire pressurisable tubes, or modified probes made from beryllium-copper or titanium alloys. ${ }^{13 b, 16}$ In the absence of a reference frequency for the solvent $\mathrm{CD}_{2} \mathrm{HCN}$ signal, our approach was to instead remove the lock on the $\mathrm{CD}_{2} \mathrm{HCN}$ signal such that it would shift with varying pressure.

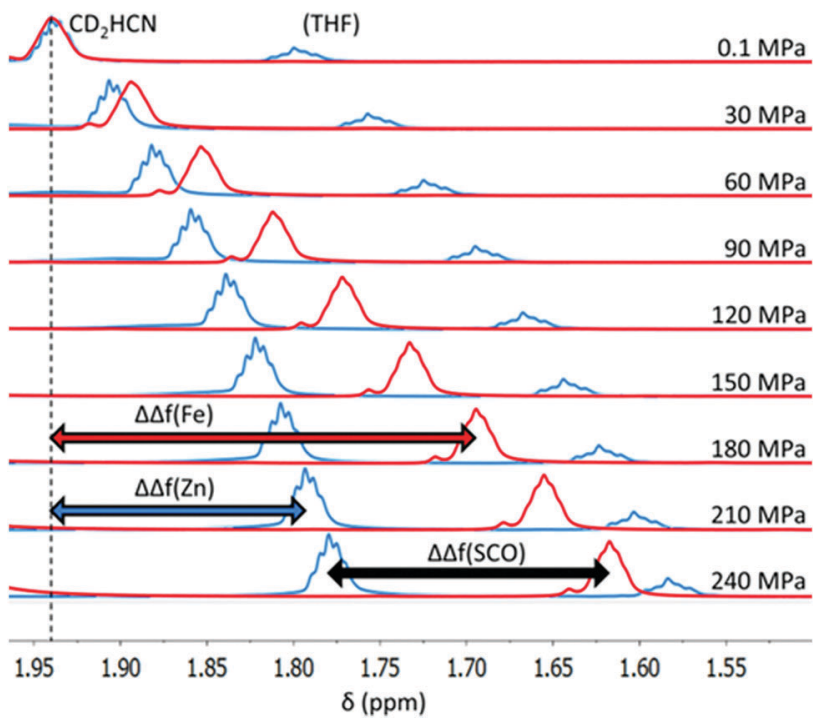

Fig. 3 Frequency shift of the $\mathrm{CD}_{2} \mathrm{HCN}$ signal for $\left[\mathrm{Fe}_{2}(\mathrm{PSPhT})_{2}\right]\left(\mathrm{BF}_{4}\right)_{4}$ (red spectra) and the diamagnetic analogue $\left[\mathrm{Zn}_{2}\left(\mathrm{PS}^{\mathrm{i}} \mathrm{BuT}\right)_{2}\right]\left(\mathrm{BF}_{4}\right)_{4}$ (blue spectra) from $0.1 \mathrm{MPa}$ to $240 \mathrm{MPa}$ at $293 \mathrm{~K}$. The magnitude of the shifts, $\Delta \Delta f(\mathrm{Fe})$ and $\Delta \Delta f(\mathrm{Zn})$, for the $\mathrm{Fe}(॥)$ and $\mathrm{Zn}(\|)$ solutions respectively, are indicated, as well as their difference, $\Delta \Delta f$ (SCO), which is due to a decrease in magnetic susceptibility in the $\mathrm{Fe}(I)$ solution. Note: to aid visualisation, both $\left[\mathrm{Fe}_{2}(\mathrm{PSPhT})_{2}\right]\left(\mathrm{BF}_{4}\right)_{4}$ spectra (red) and $\left[\mathrm{Zn}_{2}\left(\mathrm{PS}^{\mathrm{i}} \mathrm{BuT}\right)_{2}\right]\left(\mathrm{BF}_{4}\right)_{4}$ spectra (blue) are manually referenced such that the $\mathrm{CD}_{2} \mathrm{HCN}$ signal is at $1.94 \mathrm{ppm}$ at $0.1 \mathrm{MPa}$, because $\Delta \Delta f(\mathrm{Fe}), \Delta \Delta f(\mathrm{Zn})$, and $\Delta \Delta f(\mathrm{SCO})$ are defined as relative to atmospheric pressure.

The frequency shift at each pressure relative to atmospheric pressure is defined as $\Delta \Delta f$ (Fig. 3). This quantity could then be added to the known frequency shift from that in pure $\mathrm{CD}_{3} \mathrm{CN}$ at atmospheric pressure, $\Delta f^{0}$ (determined from our previous variable temperature Evans method data on these complexes), ${ }^{17}$ to obtain $\Delta f$ and hence $\chi_{\mathrm{g}}$ from eqn (1), and therefore $\chi_{\mathrm{M}} T$ at each pressure.

For each $\mathrm{Fe}(\mathrm{II})$ solution, as the pressure increased the $\mathrm{CD}_{2} \mathrm{HCN}$ signal shifted upfield (Fig. 3), resulting in increasingly negative values of $\Delta \Delta f(\mathrm{Fe})$ (Fig. 3, red), which is consistent with the SCO towards the LS state. However, with the lock signal off, the $\mathrm{CD}_{2} \mathrm{HCN}$ peak will gradually drift upfield with time in the absence of any pressure/temperature changes or change in magnetic susceptibility of the sample. This is due to the magnetic field strength of the NMR slowly, and reliably, decreasing with time after tuning. The magnitude of this effect is small in comparison to the signal shift upon pressure changes, but nonetheless time corrections were applied to $\Delta \Delta f(\mathrm{Fe})$ values to minimise error (see the $\mathrm{ESI} \dagger$ for details).

A correction must also be made for the $\mathrm{CD}_{2} \mathrm{HCN}$ signal frequency shift with increasing pressure for a diamagnetic solution, so that the magnitude of the shift in the Fe(II) solution due to the SCO can be ascertained. For this purpose, the Zn(II) analogues of each complex, $\left[\mathrm{Zn}_{2}(\mathbf{P S R T})_{2}\right]\left(\mathrm{BF}_{4}\right)_{4}$, were synthesised (see the ESI $\dagger$ ). Typically in paramagnetic NMR studies, a free ligand is used as a diamagnetic reference; however, as this is the first high-pressure NMR magnetic susceptibility study, in order to check for any unforeseen chaotrope/kosmotrope effects with 

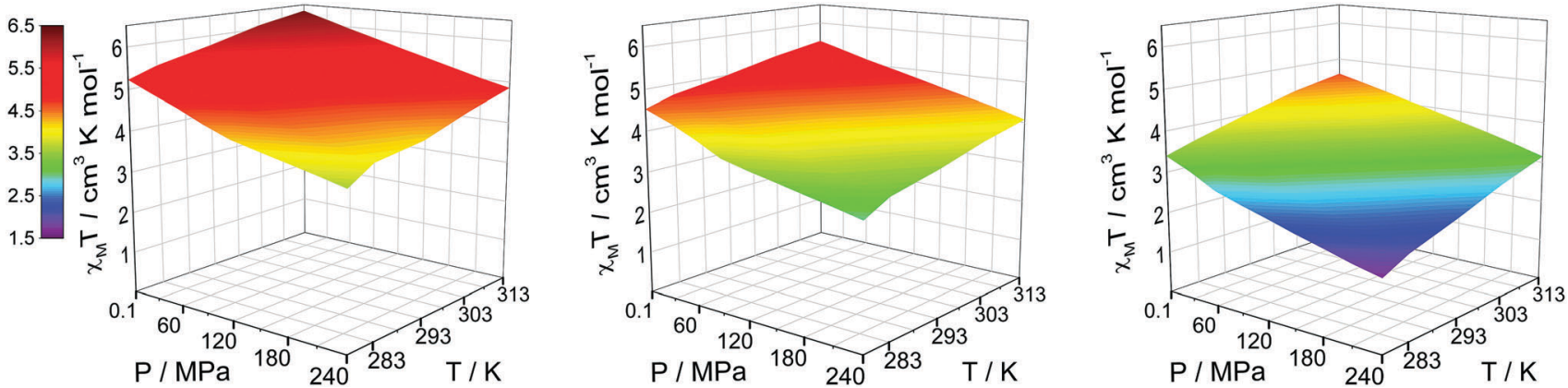

Fig. $4 \chi_{M} T$ vs. pressure vs. temperature for $\mathrm{CD}_{3} \mathrm{CN}$ solutions of (left) $\left[\mathrm{Fe}_{2}(\mathrm{PSPhT})_{2}\right]\left(\mathrm{BF}_{4}\right)_{4}$, (centre) $\left[\mathrm{Fe}_{2}\left(\mathrm{PS}^{\mathrm{Me}} \mathrm{PhT}_{2}\right]\left(\mathrm{BF}_{4}\right)_{4}\right.$, and $(\mathrm{right})\left[\mathrm{Fe}_{2}\left(\mathrm{PS}^{\mathrm{i}} \mathrm{BuT}_{2}\right]\left(\mathrm{BF}_{4}\right)_{4}\right.$. The colour coding shows the wide and varied magnetic responses across the three complexes as a function of temperature and pressure.

varying pressure, the $\mathrm{Zn}(\mathrm{II})$ complexes, which are of the same size, shape and charge as the $\mathrm{Fe}(\mathrm{II})$ complexes and so were considered to be superior to the free ligands, were also tested. Conveniently, this test demonstrates that the free ligand is in fact a perfectly acceptable diamagnetic reference, as it responds in the same way as the $\mathrm{Zn}(\mathrm{II})$ complexes do (Fig. S4, ESI $\dagger$ ). ${ }^{1} \mathrm{H}$ NMR spectra of the $\mathrm{Zn}$ (II) analogues, at the same concentration in $\mathrm{CD}_{3} \mathrm{CN}$ as the corresponding $\mathrm{Fe}(\mathrm{II})$ complexes, were recorded to determine the frequency shift of $\mathrm{CD}_{2} \mathrm{HCN}$ relative to atmospheric pressure for the diamagnetic $\mathrm{Zn}$ (II) solutions, defined as $\Delta \Delta f(\mathrm{Zn})$ (Fig. 3, blue). This enabled point-by-point corrections, for $\Delta \Delta f(\mathrm{Zn})$ at each pressure and temperature investigated, to be made to the $\mathrm{Fe}(\mathrm{II})$ spectra. The resulting $\Delta \Delta f(\mathrm{SCO})=\Delta \Delta f(\mathrm{Fe})-\Delta \Delta f(\mathrm{Zn})$ values are the frequency shifts of $\mathrm{CD}_{2} \mathrm{HCN}$ relative to atmospheric pressure due only to a change in magnetic susceptibility of the Fe(II) solution (Fig. 3).

From the known $\chi_{M} T$ at atmospheric pressure, ${ }^{17}$ eqn (1) can be used to calculate the $\Delta f$ for the particular temperature and concentration of the $\mathrm{Fe}$ (II) solution, which we label $\Delta f^{0}$, the frequency shift of $\mathrm{CD}_{2} \mathrm{HCN}$ at atmospheric pressure relative to that of an internal reference standard of pure $\mathrm{CD}_{3} \mathrm{CN}$, if it was present in the high pressure cell. $\Delta \Delta f(\mathrm{SCO})$ is then the change in this frequency shift, arising from the change in spin state only, as pressure is applied. Hence, the frequency shift of $\mathrm{CD}_{2} \mathrm{HCN}$ at each pressure relative to pure $\mathrm{CD}_{3} \mathrm{CN}$ at that pressure is obtained simply by $\Delta f=\Delta f^{0}+\Delta \Delta f(\mathrm{SCO})$. Finally, $\chi_{\mathrm{g}}$ at each pressure can then be calculated from these $\Delta f$ values using eqn (1), considering the changes in the density of acetonitrile (and hence concentration of the complex), to give a quantitative description of the spin state at any pressure/temperature.

Applying this method to $\mathrm{CD}_{3} \mathrm{CN}$ solutions of $\left[\mathrm{Fe}_{2}(\mathbf{P S R T})_{2}\right]\left(\mathrm{BF}_{4}\right)_{4}$ reveals the solution $\mathrm{SCO}$ induced by both pressure and temperature for each of the three complexes (Fig. 4, Fig. S7-S12, and Tables S9-S11, ESI $\dagger$ ). The SCO is gradual and incomplete within the pressure range available. The $\left[\mathrm{Fe}_{2}(\mathbf{P S R T})_{2}\right]\left(\mathrm{BF}_{4}\right)_{4}$ series of complexes are potential candidates for solution sensor applications, i.e. for simultaneous sensing of pressure and temperature in solution over, in particular, a wide range of pressure, based on their different magnetic susceptibility responses. ${ }^{18}$

The proton signals observed in the ${ }^{1} \mathrm{H}$ NMR spectrum (Fig. 2) are the population-weighted average signals of the HS and LS states, and therefore the extent to which the signals are shifted from the fully LS spectrum reflects the magnetic susceptibility of the complex in solution. Assuming the ideal Curie behaviour, the chemical shift, $\delta$, of a proton signal has a linear relationship with $\chi_{\mathrm{M}}{ }^{11 b}$ This allows for the correlation of the processed data, $\chi_{\mathrm{M}}$, as calculated by our adapted Evans method, with raw $\delta$ spectral data for pyridyl protons py-H4 and py-H5 (Fig. 5 and Fig. S14-S19, ESI $\dagger$ ). Indeed good linear relationships are observed, indicating a high level of accuracy in the adapted high pressure Evans method of calculating $\chi_{\mathrm{M}}$ or $\chi_{\mathrm{M}} T$.

The most significant error here is in knowing the exact concentration of the solutions used, which is always the case for the standard Evans method and typically results in $5-10 \%$ error. ${ }^{19}$ The error associated with the extra corrections needed (time, $\mathrm{Zn}$ analogues) for our adapted method is smaller (3-5\%) and contains the error in accurately reading the signal position, which is also present in the standard method. Therefore, no significantly large errors are introduced through our extension

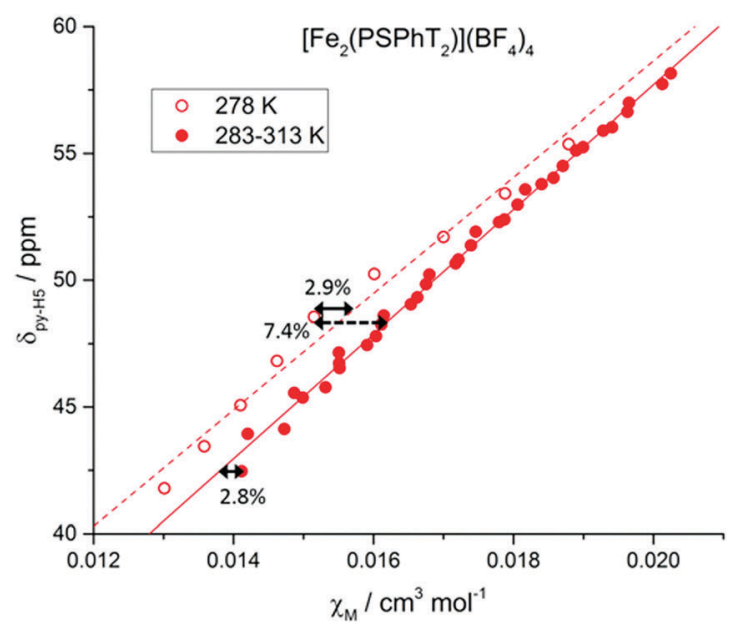

Fig. $5 \delta$ (py-H5) vs. $\chi_{M}$ for $\left[\mathrm{Fe}_{2}^{\prime \prime}(\mathrm{PSPhT})_{2}\right]\left(\mathrm{BF}_{4}\right)_{4}$ in $\mathrm{CD}_{3} \mathrm{CN}$ at variable pressure/ temperature. Hollow data points represent the spectra recorded at $278 \mathrm{~K}$ in one solution, with the linear fit shown as the dashed line. Solid data points recorded on another solution at 283-313 K, with a solid line for the linear fit. For the $\chi_{\mathrm{M}}$ values calculated for $\left[\mathrm{Fe}_{2}^{\prime \prime}\left(\mathrm{PSPhT}_{2}\right]\left(\mathrm{BF}_{4}\right)_{4}\right.$, the maximum error between data points for the same solution is $2.8-2.9 \%$, and the maximum error between data points for different solutions is $7.4 \%$. See the ESI† for more details. 
of the Evans method from a tube-in-tube method to a single tube method that can be applied to the study of pressure and temperature effects.

It is possible to calculate the fraction $\mathrm{HS}, \gamma_{\mathrm{HS}}$, directly from proton chemical shifts ${ }^{11 b, c}$ instead of using the Evans method. However, these methods require a fully $\mathrm{HS}$ baseline to be reached $^{11 b}$ and/or a very wide $(200 \mathrm{~K})$ temperature range. ${ }^{11 c}$ Although our method requires careful application of corrections, it produces quantitative $\chi_{\mathrm{M}} T$ values (but not $\gamma_{\mathrm{HS}}$ ) and can operate in narrow ranges of magnetic susceptibility and temperature.

We have described a robust method for determining the spin states quantitatively in high-pressure solutions. In the test case of the $\left[\mathrm{Fe}_{2}(\mathbf{P S R T})_{2}\right]\left(\mathrm{BF}_{4}\right)_{4}$ complexes, an SCO was observed, and the spin state is tuned by both pressure and temperature in solution, raising the possibility of solution-based simultaneous pressure/temperature sensing. Unlike a thermally induced SCO, which is limited by the freezing/boiling points of the solvent, the pressure is limited only by instrumentation and so has the potential to allow access to a much wider range of spin states in solution. Although applied here only to simple Fe(II) SCO compounds, this robust method could be extended to study the effects of pressure on spin-labile (bio)catalysts, sensors or host-guest chemical processes.

We thank the University of Otago (for a PhD scholarship to RWH), the Marsden Fund administered by the Royal Society of New Zealand (UOO1318 to SB and 09-MAU-140 to GBJ) and the Allan Wilson Centre for Molecular Evolution and Ecology for supporting this research.

\section{Conflicts of interest}

There are no conflicts to declare.

\section{References}

1 (a) E. Coronado, P. Delhaès, D. Gatteschi and J. S. Miller, Molecular Magnetism: From Molecular Assemblies to the Devices, Springer, Netherlands, Dordrecht, 1996; (b) M. A. Halcrow, Spin-Crossover Materials: Properties and Applications, John Wiley \& Sons, Ltd, Chichester, 1st edn, 2013; (c) O. Kahn, Molecular Magnetism, VCH Publishers Inc., New York, 1993; (d) R. Sessoli, D. Gatteschi, A. Caneschi and M. A. Novak, Nature, 1993, 365, 141-143.

2 (a) J. N. Harvey, R. Poli and K. M. Smith, Coord. Chem. Rev., 2003, 238-239, 347-361; (b) R. Poli, Chem. Rev., 1996, 96, 2135-2204.

3 (a) Y.-Y. Jiang, J.-L. Jiang and Y. Fu, Organometallics, 2016, 35, 3388-3396; (b) D. Schröder, S. Shaik and H. Schwarz, Acc. Chem. Res., 2000, 33, 139-145; (c) P. L. Holland, Acc. Chem. Res., 2015, 48, 1696-1702; (d) R. B. Bedford, Acc. Chem. Res., 2015, 48, 1485-1493; (e) S. B. Muñoz Iii, S. L. Daifuku, W. W. Brennessel and M. L. Neidig, J. Am. Chem. Soc., 2016, 138, 7492-7495.

4 (a) J. C. De Paula and G. W. Brudvig, J. Am. Chem. Soc., 1985, 107, 2643-2648; (b) R. Chatterjee, G. Han, J. Kern, S. Gul, F. D. Fuller, A. Garachtchenko, I. D. Young, T.-C. Weng, D. Nordlund, R. AlonsoMori, U. Bergmann, D. Sokaras, M. Hatakeyama, V. K. Yachandra and J. Yano, Chem. Sci., 2016, 7, 5236-5248; (c) V. Krewald, M. Retegan, F. Neese, W. Lubitz, D. A. Pantazis and N. Cox, Inorg. Chem., 2016, 55, 488-501; (d) H. Kim, J. Park, I. Park, K. Jin, S. E. Jerng, S. H. Kim, K. T. Nam and K. Kang, Nat. Commun., 2015, 6, 8253; (e) V. Krewald, M. Retegan, N. Cox, J. Messinger, W. Lubitz, S. DeBeer, F. Neese and D. A. Pantazis, Chem. Sci., 2015, 6, 1676-1695.

5 (a) A. R. McDonald and L. Que Jr, Coord. Chem. Rev., 2013, 257, 414-428; (b) Y. Sugiura, J. Kuwahara, T. Nagasawa and H. Yamada, J. Am. Chem. Soc., 1987, 109, 5848-5850; (c) A. J. Boone, C. H. Chang, S. N. Greene, T. Herz and N. G. J. Richards, Coord. Chem. Rev., 2003, 238-239, 291-314; (d) D. Sahoo, M. G. Quesne, S. P. de Visser and S. P. Rath, Angew. Chem., Int. Ed., 2015, 54, 4796-4800; (e) R.-J. Cheng, P.-Y. Chen, P.-R. Gau, C.-C. Chen and S.-M. Peng, J. Am. Chem. Soc., 1997, 119, 2563-2569.

6 (a) P. Gütlich, V. Ksenofontov and A. B. Gaspar, Coord. Chem. Rev., 2005, 249, 1811-1829; (b) H. G. Drickamer and C. W. Frank, Electronic Transitions and the High Pressure Chemistry and Physics of Solids, Springer, Netherlands, Dordrecht, 1973, pp. 126-151.

7 (a) A. H. Ewald, R. L. Martin, E. Sinn and A. H. White, Inorg. Chem., 1969, 8, 1837-1846; (b) A. H. Ewald, R. L. Martin, I. G. Ross and A. H. White, Proc. R. Soc. London, Ser. A, 1964, 280, 235-257.

8 W. S. Hammack, A. J. Conti, D. N. Hendrickson and H. G. Drickamer, J. Am. Chem. Soc., 1989, 111, 1738-1741.

9 O. Troeppner, R. Lippert, T. E. Shubina, A. Zahl, N. Jux and I. Ivanović-Burmazović, Angew. Chem., Int. Ed., 2014, 53, 11452-11457. 10 D. F. Evans, J. Chem. Soc., 1959, 2003-2005.

11 (a) I. Bertini, C. Luchinat, G. Parigi and E. Ravera, NMR of Paramagnetic Molecules, Elsevier, Boston, 2nd edn, 2017, pp. 1-24; (b) B. Weber and F. A. Walker, Inorg. Chem., 2007, 46, 6794-6803; (c) H. Petzold, P. Djomgoue, G. Horner, J. M. Speck, T. Ruffer and D. Schaarschmidt, Dalton Trans., 2016, 45, 13798-13809; (d) C. Piguet, E. Rivara-Minten, G. Bernardinelli, J.-C. G. Bunzli and G. Hopfgartner, J. Chem. Soc., Dalton Trans., 1997, 421-434; (e) K. L. Bren, Spin States in Biochemistry and Inorganic Chemistry, John Wiley \& Sons, Ltd, 2015, pp. 409-434; $(f)$ Z. Ni and M. P. Shores, J. Am. Chem. Soc., 2009, 131, 32-33.

12 A. V. Davis, D. Fiedler, G. Seeber, A. Zahl, R. van Eldik and K. N. Raymond, J. Am. Chem. Soc., 2006, 128, 1324-1333.

13 (a) L. Damoense, M. Datt, M. Green and C. Steenkamp, Coord. Chem. Rev., 2004, 248, 2393-2407; (b) C. L. Dwyer, in Comprehensive Organometallic Chemistry III, ed. R. H. Crabtree, Elsevier, Oxford, 2007, pp. 483-507.

14 R. Fourme, E. Girard and K. Akasaka, Curr. Opin. Struct. Biol., 2012, 22, 636-642.

15 C. Piguet, J. Chem. Educ., 1997, 74, 815-816.

$16 \mathrm{~J}$. Jonas, in High Pressure Molecular Science, ed. R. Winter and J. Jonas, Springer, Netherlands, Dordrecht, 1999, pp. 231-259.

17 R. W. Hogue, H. L. C. Feltham, R. G. Miller and S. Brooker, Inorg. Chem., 2016, 55, 4152-4165.

18 (a) J. Linares, E. Codjovi and Y. Garcia, Sensors, 2012, 12, 4479-4492; (b) C.-M. Jureschi, J. Linares, A. Boulmaali, P. Dahoo, A. Rotaru and Y. Garcia, Sensors, 2016, 16, 187; (c) K. Y. Maryunina, X. Zhang, S. Nishihara, K. Inoue, V. A. Morozov, G. V. Romanenko and V. I. Ovcharenko, J. Mater. Chem. C, 2015, 3, 7788-7791.

19 L. A. Yatsunyk and F. A. Walker, Inorg. Chem., 2004, 43, 757-777. 